\title{
METHODS - A randomised controlled trial of METhotrexate to treat Hand Osteoarthritis with Synovitis: study protocol for a randomised controlled trial
}

\author{
Yuanyuan Wang ${ }^{1}$, Andrew J. Teichtahl' ${ }^{1}$, Graeme Jones ${ }^{2}$, Helen I. Keen ${ }^{3,4}$, Catherine L. Hill ${ }^{5,6}$, Anita E. Wluka', \\ Jessica Kasza ${ }^{1}$ and Flavia M. Cicuttini ${ }^{{ }^{*}}$
}

\begin{abstract}
Background: Hand osteoarthritis is a common and disabling problem without effective therapies. Accumulating evidence suggests the role of local inflammation in causing pain and structural progression in hand osteoarthritis, and hand osteoarthritis with synovitis is a commonly encountered clinical phenotype. Methotrexate is a well-established, low-cost, and effective treatment for inflammatory arthritis with a well-described safety profile. The aim of this multicentre, randomised, double-blind, placebo-controlled trial is to determine whether methotrexate reduces pain over 6 months in patients with hand osteoarthritis and synovitis.
\end{abstract}

Methods: Ninety-six participants with hand osteoarthritis and synovitis will be recruited through the Osteoarthritis Clinical Trial Network (Melbourne, Hobart, Adelaide, and Perth), and randomly allocated in a 1:1 ratio to receive either methotrexate $20 \mathrm{mg}$ or identical placebo once weekly for 6 months. The primary outcome is pain reduction (assessed by $100 \mathrm{~mm}$ visual analogue scale) at 6 months. The secondary outcomes include changes in physical function and quality of life assessed using Functional Index for Hand Osteoarthritis, Australian Canadian Osteoarthritis Hand Index, Health Assessment Questionnaire, Michigan Hand Outcomes Questionnaire, Short-Form-36, tender and swollen joint count, and grip strength, and structural progression assessed using progression of synovitis and bone marrow lesions from magnetic resonance imaging and radiographic progression at 6 months. Adverse events will be recorded. The primary analysis will be by intention to treat, including all participants in their randomised groups.

Discussion: This study will provide high-quality evidence to address whether methotrexate has an effect on reducing pain over 6 months in patients with hand osteoarthritis and synovitis, with major clinical and public health importance. While a positive trial will inform international clinical practice guidelines for the management of hand osteoarthritis, a negative trial would be highly topical and change current trends in clinical practice.

Trial registration: Australian New Zealand Clinical Trials Registry (ANZCTR), ACTRN12617000877381. Registered 15 June 2017, https://www.anzctr.org.au/Trial/Registration/TrialReview.aspx?id=373124

Keywords: Methotrexate, Osteoarthritis, Hand, Pain, Function

*Correspondence: Flavia.Cicuttini@monash.edu

${ }^{1}$ Department of Epidemiology and Preventive Medicine, School of Public Health and Preventive Medicine, Monash University, 553 St Kilda Road, Melbourne, VIC 3004, Australia

Full list of author information is available at the end of the article

\section{Background}

Osteoarthritis (OA) is the most common chronic joint disease and frequently involves the hand [1]. Hand OA is a common and disabling problem worldwide, resulting original author(s) and the source, provide a link to the Creative Commons licence, and indicate if changes were made. The images or other third party material in this article are included in the article's Creative Commons licence, unless indicated otherwise in a credit line to the material. If material is not included in the article's Creative Commons licence and your intended use is not permitted by statutory regulation or exceeds the permitted use, you will need to obtain permission directly from the copyright holder. To view a copy of this licence, visit http://creativecommons.org/licenses/by/4.0/. The Creative Commons Public Domain Dedication waiver (http://creativeco mmons.org/publicdomain/zero/1.0/) applies to the data made available in this article, unless otherwise stated in a credit line to the data. 
in significant disease burden and impaired quality of life. Most middle-aged people have radiographic OA affecting at least one hand joint, with $20 \%$ having disabling pain [2]. The age-standardised prevalence of hand OA was $44.2 \%$ for females and $37.7 \%$ for males in the general population [3], much higher than the prevalence of rheumatoid arthritis $(\sim 1 \%)$. Hand OA is as disabling as rheumatoid arthritis, impeding activities of daily living such as dressing and eating [4], and has similar clinical importance with regard to health-related quality of life as rheumatoid arthritis [5]. Since the prevalence of hand OA increases with age, the ageing population is expected to drive increasing disease burden and healthcare costs for treating this condition [6]. Despite the high prevalence and disease burden, there is a lack of effective therapies for hand OA. Clinical guidelines for the management of hand OA, such as those from the European League Against Rheumatism suggest topical therapy (preferred over systemic treatments, topical non-steroidal antiinflammatory drugs (NSAIDs) being first-line choice), oral analgesics (e.g. paracetamol and NSAIDs), and nonpharmacological therapy (education, assistive devices, exercises and orthoses) [7]. However, these therapies only have limited efficacy in reducing pain.

Accumulating evidence suggests that hand $\mathrm{OA}$ is a heterogeneous disease involving all joint structures, in which local inflammation plays a central role in causing pain and structural progression [8]. A common phenotype of hand OA is the inflammatory phenotype, characterised by joint swelling (synovitis) $[9,10]$, and this phenotype represents an aggressive form of disease [11-14]. Imaging studies have shown a high prevalence (approximately $50 \%)$ of synovitis in symptomatic hand OA $[15,16]$, with painful joints significantly more likely to have synovitis than non-painful joints $[15,17,18]$. Synovitis is the strongest predictor for radiographic progression of hand OA over 2 years $[11,12]$ and 5 years [13, 14], supporting inflammation is a risk factor for rapid disease progression. Therefore, inflammation is a potential treatment target in hand $\mathrm{OA}$, and therapies targeting synovitis may offer a novel approach for reducing disease burden from hand OA.

Recent efforts to examine the effect of anti-inflammatory therapies in hand OA have been limited by including all patients with hand OA, not just those with the synovitis phenotype. A randomised controlled trial showed adalimumab (a tumour necrosis factor blocker) was not superior to placebo to alleviate pain in patients with hand OA not responding to analgesics and NSAIDs [19]. This study was limited by the short duration (6 weeks) and no specific phenotype (i.e. with synovitis) of hand OA being examined. There is proof of concept that targeting synovitis will be effective. In a 1-year randomised controlled trial of patients with symptomatic erosive inflammatory hand OA, etanercept (a tumour necrosis factor blocker) resulted in greater pain reduction, more radiographic remodeling, and less bone marrow lesions compared to placebo in those with inflammation [20]. In another 12-month randomised controlled trial of people with erosive hand $\mathrm{OA}$, adalimumab significantly halted the progression of joint damage in those with synovitis [21]. Based on the histology of the synovium in hand OA [22], there is no biological rationale why specific therapies targeting one inflammatory pathway, such as tumour necrosis factor antagonists, provide effective treatments for hand OA with synovitis. Less specific therapies may offer greater disease modification, since multiple preinflammatory cytokines are targeted. Methotrexate is a well-established, low-cost, and effective treatment for inflammatory arthritis with a well-described safety profile. In a Cochrane review of 7 randomised controlled trials comparing methotrexate with placebo in rheumatoid arthritis, methotrexate monotherapy showed a clinically important and statistically significant improvement in symptoms at 52 weeks and significant reduction in radiographic progression [23]. Methotrexate reduced pain in a randomised controlled trial over 6 months and an openlabel trial over 24 weeks of knee OA [24, 25]. However, a recently published randomised controlled trial showed no superiority of $10 \mathrm{mg}$ methotrexate weekly over placebo in pain relief at 3 or 12 months in patients with symptomatic erosive hand OA refractory to usual treatments [26]. This study may be limited by the very low dose of methotrexate (10 mg weekly) and not inflammatory phenotype of hand OA being examined. Based on the available data, it is clinically important to determine whether targeting those with hand OA and synovitis is likely to improve the effectiveness of methotrexate on reducing pain and/or slowing structural progression of hand OA.

\section{Hypothesis and objectives}

We propose a randomised, double-blind, placebo-controlled trial to determine the effect of $20 \mathrm{mg}$ methotrexate weekly, compared to placebo, on reducing clinical symptoms and structural progression in people with hand OA and synovitis over 6 months. It was hypothesised that methotrexate will (1) reduce pain (primary hypothesis), and (2) improve physical function and quality of life (secondary hypothesis), and reduce structural progression (secondary hypothesis) over 6 months compared to placebo in people with symptomatic hand OA and synovitis. If methotrexate is proven to be effective, it will offer a novel therapeutic approach to reducing pain and disease progression of hand OA. 


\section{Study design}

The METHODS (A randomised controlled trial of METhotrexate to treat Hand Osteoarthritis with Synovitis) study is a multicentre, randomised, double-blind, placebo-controlled trial over 6 months.

\section{Trial registration}

The trial was registered at the Australian New Zealand Clinical Trials Registry prior to recruitment commencing (ACTRN12617000877381, registered 15 June 2017; amended 22 July 2021). The trial reporting will be guided by the Consolidated Standards of Reporting Trials (CONSORT) Statement [27]. Due to the COVID-19 pandemic, the trial was temporarily halted in March 2020, when 80 participants had been randomised with 60 participants taking study medication for at least 6 months. Due to potential safety concerns at that time, participants were asked to stop study medication. The trial was resumed in November 2020. The 7 months when participants were off treatment due to safety concerns regarding the possibility of COVID infection in those taking methotrexate, would interfere with the validity of the use of the primary outcomes assessed at 2 years for hand pain and radiographic progression. However, the use of pain measured at 6 months will provide a valid measure to test whether methotrexate improves pain. In November 2020, the protocol was amended to make pain reduction at 6 months as the primary outcome, and radiographic progression at 6 months as a secondary outcome. Accordingly, the other secondary outcomes were also amended, which included changes in physical function, quality of life, joint activity, and grip strength at 6 months, and progression of synovitis and bone marrow lesion at 6 months after the amendment. The amendment was submitted to the Australian New Zealand Clinical Trials Registry in November 2020 and updated in July 2021.

\section{Ethics approval}

Ethics approval has been obtained from Alfred Hospital Ethics Committee (290/17), Monash University Human Research Ethics Committee (10725), University of Tasmania Human Research Ethics Committee (H0016794), Central Adelaide Local Health Network Human Research Ethics Committee (HREC/18/CALHN/458), and South Metropolitan Health Service Human Research Ethics Committee (RGS0000000573). Written informed consent will be obtained from all the participants.

\section{Methods}

\section{Study setting and participants}

Eligible participants with hand OA and synovitis will be recruited through the Osteoarthritis Clinical Trial Network (Melbourne, Hobart, Adelaide, and Perth,
Australia), from the community via advertisements and from medical practitioners.

\section{Inclusion criteria}

(1) aged 40-75 years; (2) a pain score of at least 40 on a $100 \mathrm{~mm}$ visual analogue scale (VAS) and radiological OA (Kellgren and Lawrence grade $\geq 2$ ) in $\geq 1$ joint, as recommended by the Osteoarthritis Research Society International (OARSI) clinical trials guidelines for hand OA [28]; (3) evidence of synovitis determined from magnetic resonance imaging (MRI) according to the Outcome Measures in Rheumatology (OMERACT) hand OA recommendations and with a grade $\geq 1$ in $\geq 1$ joint [29].

\section{Exclusion criteria}

(1) concomitant rheumatic disease, inflammatory joint disease, psoriatic arthritis, ankylosing spondylitis, or gout; (2) contraindication to methotrexate [e.g. renal, liver or haematological condition, cancer including skin cancer, serious infections requiring hospitalisation in the last 5 years, known or past infection with human immunodeficiency virus, hepatitis $\mathrm{B}$ or $\mathrm{C}$, tuberculosis, or known lung disease with scarring (any fibrosis or evidence of past tuberculosis exposure on chest $\mathrm{x}$-ray), concurrent regular prednisolone use, taking regular trimethoprim or bactrim antibiotics, egg or flu vaccination allergy]; (3) contraindication to MRI (e.g. implanted pacemaker, metal sutures, presence of shrapnel or iron filings in the eye, or claustrophobia); (4) unable to complete informed consent; (5) women who are pregnant, breast-feeding or trying to become pregnant, or men who father a child.

\section{Study timeline}

This trial began recruitment in August 2017. It is estimated to accomplish recruitment in November 2021 and complete the 6-month follow-up and data collection in May 2022. Figure 1 shows trial participation and study procedure.

\section{Randomisation, allocation concealment, and blinding}

Allocation of participants in a 1:1 ratio to one of the two groups will be based on computer generated random numbers prepared by a statistician with no involvement in the trial. Block randomisation will be performed, stratified by study site and gender, given that hand OA disproportionately influences a larger number of females than males. The use of a central automated allocation procedure with security in place will ensure the allocation cannot be accessed or influenced by any person. Participants, assessors and statisticians will be blinded to group allocation. Allocation concealment and double blinding will be ensured by: (1) medications being dispensed by hospital 


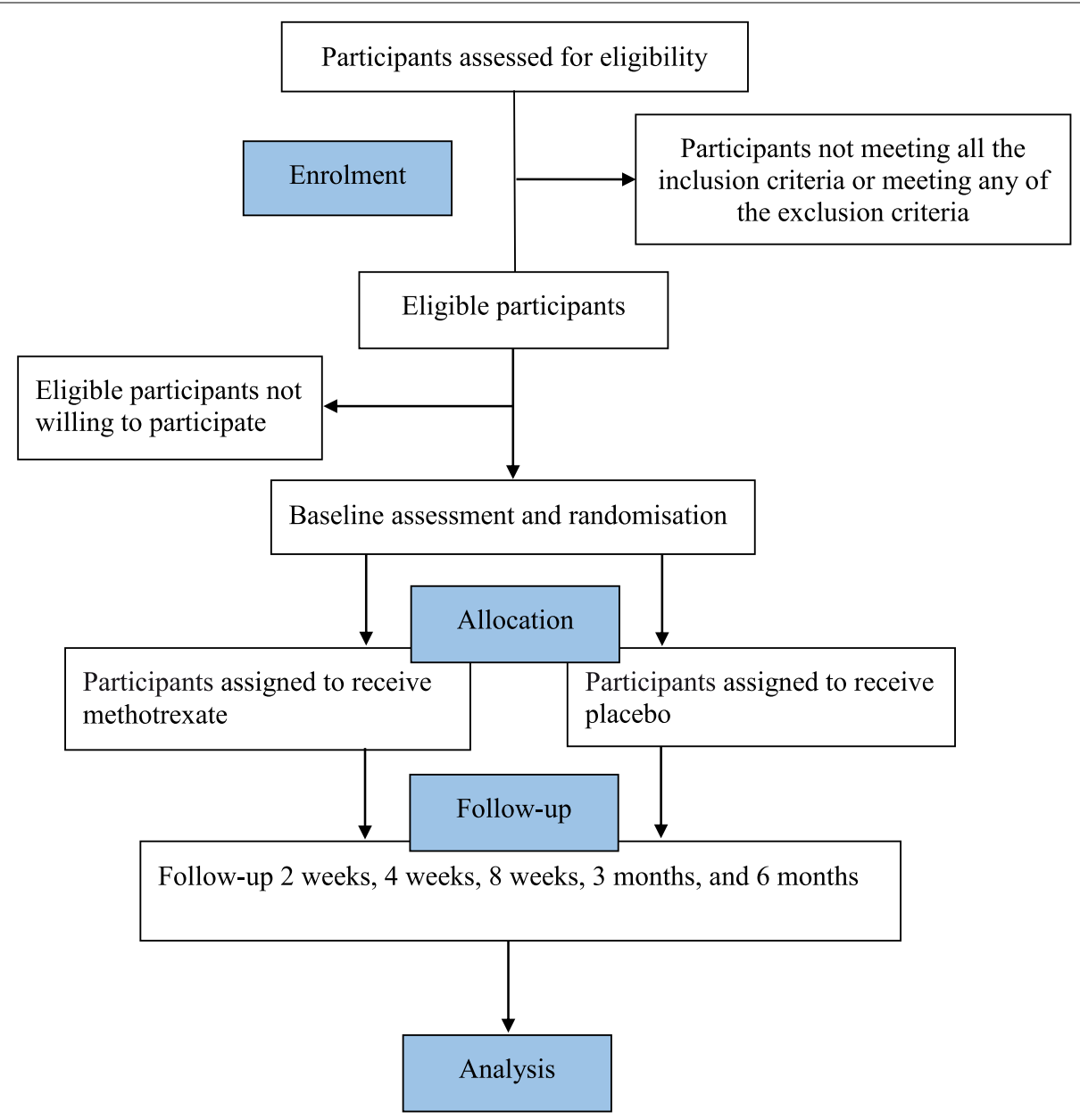

Fig. 1 Flowchart of trial participation

clinical trial pharmacy at each site; (2) use of an identical placebo tablet; (3) subjective measures being taken by research assistants blinded to group allocation; (4) objective measures of structural progression being made by trained observers blinded to group allocation and time sequence of imaging. Emergency unblinding will be allowed in limited situations that impact on the safety of study participants. Code-break for the full randomisation schedule will be maintained by the administering institute. Tamper-proof unblinding envelopes, provided by the drug company preparing the study medication, will be used in case of the need for emergency unblinding. Participants who are unblinded will be withdrawn from treatment and be requested to complete questionnaires and have a follow-up hand x-ray and MRI scan at 6 months. Given the possible toxicities related to methotrexate, there is potential for investigators reviewing blood test results to become aware of treatment. Therefore, patient-reported outcomes will be assessed before any changes in dose or results of monitoring blood test are discussed with participants. The investigators with knowledge of blood test results will not be responsible for administering questionnaires.

\section{Intervention}

Participants will be randomised to receive methotrexate (10 mg tablets) or placebo. Placebo will be manufactured to have same colour, taste and smell as methotrexate tablets.

\section{Dosing}

Methotrexate is currently used in rheumatoid arthritis, commonly dosed at $20 \mathrm{mg}$ per week. Given that synovitis predates rapidly progressive radiographic hand OA [11, 12], and to alleviate concerns around inefficacy due to inadequate dosing, we will follow current guidelines for use of methotrexate in rheumatoid arthritis. The maximum dose will be $20 \mathrm{mg}$ per week [30]. Participants will be prescribed $10 \mathrm{mg}$ methotrexate or placebo weekly for four weeks, followed by $20 \mathrm{mg}$ weekly for the remainder 
of the study if there is no toxicity as determined at the physician's discretion (Australian Rheumatology Association Medication Information Sheets). The decision for dose escalation will occur at the 4-week physician review. If intolerances occur (e.g. nausea), the decision to increase to $20 \mathrm{mg}$ weekly can be delayed until further clinical review. In a Cochrane systematic review of methotrexate monotherapy, $16 \%$ of people discontinued methotrexate within 52 weeks due to an adverse event, compared with $8 \%$ of placebo subjects [23]. All participants will be prescribed oral folic acid at a minimum dose of $5 \mathrm{mg}$ per week, to be taken on days other than when methotrexate is taken. Folic acid supplementation has been shown to ameliorate side effects of methotrexate, as well as a significant reduction in discontinuation of methotrexate [31].

\section{Safety}

An independent data and safety monitoring board will be convened, consisting of two independent clinical rheumatologists, a clinical pharmacologist experienced in methotrexate use, and a biostatistician, all with clinical trial experience. They will monitor adverse events and will meet bimonthly and provide a written report to the chief investigators. Adverse events will be recorded throughout the study and chief investigators will be notified of any serious events within 24 hours. Safety of treatment will be assessed according to monitoring guidelines. As recommended by the Australian Rheumatology Association, full blood count, liver function test and urea and electrolytes tests will be performed at screening, 2, 4, and 8 weeks, 3 and 6 months (Australian Rheumatology Association, Patient Information: Methotrexate). If the results remain abnormal despite action (such as reducing the methotrexate dose), or at clinician discretion, then study medication will be stopped. Further reviews with a rheumatologist will be performed at 4 weeks, 3 and 6 months.

\section{Compliance}

Pill counts will be performed at each clinical assessment to document compliance. Weekly telephone contact for the first 3 months will be conducted to address any concerns, as well as regular clinical reviews with a study rheumatologist (at baseline, 4 weeks, 3 and 6 months). This will help to mitigate non-compliance.

\section{Concomitant medication}

To maintain the pragmatic nature of the trial, there are no restrictions with regard to concomitant analgesic medications. The participants will be allowed to continue taking the treatments that they are taking at their screening visit for the duration of the trial. If a participant is experiencing pain and requires an increase in the dose of analgesics, then the use of paracetamol, topical or oral NSAIDs or opioids, or a combination of these will be permitted, but the reason for the dose increase and the dose used will be documented. Trimethoprim, which interacts with methotrexate, will not be permitted.

\section{Study procedure}

Table 1 shows the study procedure. Volunteers will be telephone screened before undergoing in sequential order (i) clinical assessment with a rheumatologist, chest $\mathrm{x}$-ray and blood tests [full blood count, kidney function test, liver function test, $\mathrm{C}$-reactive protein, erythrocyte sedimentation rate, rheumatoid factor, anti-cyclic citrullinated peptide antibodies, human immunodeficiency virus, Hepatitis B (sAb, sAg and cAb), Hepatitis C, and Quantiferon Gold] to assess the eligibility of the participants and ensure no contraindication to methotrexate; (ii) x-ray of both hands (standardized posteroanterior view) to confirm radiological disease; and (iii) MRI of the study hand to determine the presence of synovitis. Consent was obtained by study doctor. The symptomatic hand will be the study hand. In case of bilateral symptomatic hands, the most symptomatic hand will be the study hand. In the case of bilateral and equal symptoms, the dominant hand will be studied. Participants are able to withdraw at any time during the trial; the time and reasons will be recorded. If participants withdraw from the study, they will be requested to complete questionnaires (posted to the participants with return envelope) and have a follow-up hand $\mathrm{x}$-ray and MRI scan at 6 months or end of study where possible.

\section{Primary outcome \\ Pain reduction at 6 months}

Pain reduction at 6 months will be measured according to the recommendations of the OARSI clinical trials for symptom modification in hand OA [28]. This taskforce recommended the use of a single question pain VAS as the main outcome measure for pain in hand OA clinical trials. In a recent systematic review, VAS was most frequently used for pain assessment in hand OA, with excellent reliability, good construct validity and sensitivity to change [32].

\section{Secondary outcomes}

\section{Change in pain and function at 6 months}

At baseline and 6 months, hand pain, physical function, joint activity, and hand strength will be measured according to the OARSI recommendations of clinical trials for symptom modification in hand OA [28] using the Functional Index for Hand OA (FIHOA) [33], Australian 
Table 1 Timetable and measures to be made

\begin{tabular}{|c|c|c|c|c|c|c|c|c|}
\hline & Screening & & Double blind pe & eriod & & & & \\
\hline & $\begin{array}{l}\text { Screening } \\
\text { / baseline } \\
\text { assessment }\end{array}$ & Post-screening & $\begin{array}{l}\text { MRI \& } \\
\text { randomisation }\end{array}$ & Week 2 & Week 4 & Week 8 & Months 3 & Months 6 \\
\hline Visit/phone contact & 0 & 1 & 2 & 3 & 4 & 5 & 6 & 7 \\
\hline Informed consent ${ }^{1}$ & $x$ & & & & & & & \\
\hline Blood tests ${ }^{2}$ & & $x$ & & & & & & \\
\hline Safety blood tests ${ }^{3}$ & & & & $x$ & $x$ & $x$ & $x$ & $x$ \\
\hline Telephone follow-up & & & & $x$ & & $x$ & & \\
\hline Clinical visit & $x$ & & & & $x$ & & $x$ & $x$ \\
\hline Hand x-ray & & $x^{a}$ & & & & & & $x^{a}$ \\
\hline Chest $x$-ray ${ }^{4}$ & & $x$ & & & & & & \\
\hline Hand MRI & & & $x$ & & & & & $x$ \\
\hline Medical history including vaccination & $x$ & & & & & & $x$ & $x$ \\
\hline Medications and allergies ${ }^{1}$ & $x$ & & & & $x$ & & $x$ & $x$ \\
\hline Employment and education & $x$ & & & & & & & \\
\hline Smoking & $x$ & & & & & & & \\
\hline Alcohol consumption & $x$ & & & $x$ & $x$ & $x$ & $x$ & $x$ \\
\hline Marital status and parity & $x$ & & & & & & & \\
\hline Questionnaires & & & & & & & & \\
\hline Hand VAS & $x$ & & & & $x$ & & $x$ & $x$ \\
\hline AUSCAN, FIHOA, HAQ, MHQ & $x$ & & & & & & $x$ & $x$ \\
\hline SF-36 & $x$ & & & & & & & $x$ \\
\hline Knee WOMAC, painDETECT & $x$ & & & & & & & $x$ \\
\hline Physical examination & & & & & & & & \\
\hline $\begin{array}{l}\text { Height, weight, waist and hip circum- } \\
\text { ference }\end{array}$ & $x$ & & & & & & & \\
\hline Grip strength & $x$ & & & & & & $x$ & $x$ \\
\hline Tender/swollen joint count ${ }^{1}$ & $x$ & & & & $x$ & & $x$ & $x$ \\
\hline $\begin{array}{l}\text { Cardiovascular (including blood } \\
\text { pressure), respiratory, abdominal, skin } \\
\text { examination }\end{array}$ & $x$ & & & & & & & \\
\hline Compliance and safety (AEs) $)^{1}$ & & & & $x$ & $x$ & $x$ & $x$ & $x$ \\
\hline Dispense medication & & & $x$ & & & & $x$ & \\
\hline Pill count & & & & & $x$ & & $x$ & $x$ \\
\hline
\end{tabular}

MRI magnetic resonance imaging, VAS Visual Analogue Scale, AUSCAN Australian Canadian Osteoarthritis Hand Index, FIHOA Functional Index for Hand Osteoarthritis, $H A Q$ Health Assessment Questionnaire, MHQ Michigan Hand Outcomes Questionnaire, WOMAC Western Ontario and McMaster Universities Osteoarthritis Index, AE adverse event

a Baseline and follow-up x-ray performed at the same centre using a standardized protocol

${ }^{1}$ To be performed/reviewed by study doctor

${ }^{2}$ Full blood count, kidney function test, liver function test, C-reactive protein, erythrocyte sedimentation rate, rheumatoid factor, anti-cyclic citrullinated peptide antibodies, human immunodeficiency virus, Hepatitis B (sAb, sAg and cAb), Hepatitis C, and Quantiferon Gold

${ }^{3}$ Full blood count, kidney function test, and liver function test

${ }^{4}$ Not required if chest $x$-ray in last 12 months is available

Canadian Osteoarthritis Hand Index (AUSCAN) [34], Health Assessment Questionnaire (HAQ) [35], Michigan Hand Outcomes Questionnaire (MHQ) [36], ShortForm-36 (SF-36) [37], tender and swollen joint count [38], and grip strength.

\section{Structural progression at 6 months assessed from MRI}

Participants will undergo hand MRI for screening and a repeat MRI 6 months later using a $3.0 \mathrm{~T}$ or $1.5 \mathrm{~T}$ MRI unit according to local safety rules and standardised sequences across the 4 study sites. The participant will be positioned prone with their arm above their head with a positioning frame. Details of the sequences and 


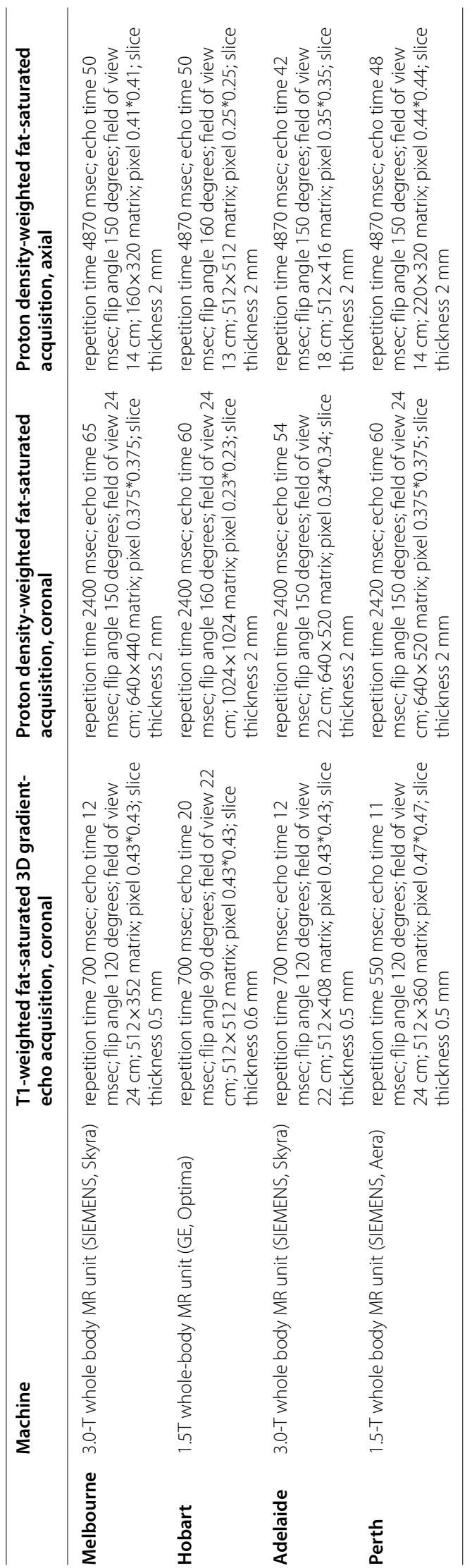


parameters are shown in Table 2. Scan time is estimated at 20 minutes. Cartilage and bone will be assessed from coronal T1-weighted and proton density-weighted images. Synovitis and tenosynovitis will be assessed from coronal and axial proton density-weighted images. MRI at baseline and 6 months will be assessed using the OMERACT hand OA score (grades 0-3) for synovitis and bone marrow lesions [29]. Readings will be performed by trained observers blinded to clinical information, time sequence of MRIs, and group allocation. Progression of synovitis or bone marrow lesions will be defined as an increase in grade $\geq 1$ from baseline to follow-up.

\section{Radiographic progression at 6 months}

Radiographs will be performed at baseline and 6 months with a standardised posteroanterior view with the beam focused on the head of the third metacarpal, using a hand map for reproducibility of position, as recommended by OARSI clinical trials for imaging in hand OA taskforce [39]. One reader will score radiographs according to the OARSI atlas for progression of hand OA [40], blind to clinical information, time sequence of $\mathrm{x}$-rays, and group allocation. Our reproducibility is high (kappa 0.7 to 0.9) [41]. Progression will be defined by any increase in Kellgren and Lawrence grade in any joint as previously described [3] and recommended by the OARSI taskforce for outcomes in clinical trials of hand OA [39], for joints with synovitis and for both hands. This method is endorsed by a systematic review as the most valid, reliable and sensitive to change [42].

\section{Other measures}

\section{Descriptive data}

Age, gender, height, weight, duration of symptoms, employment, medical history, medication use, marital status, education level, smoking, alcohol consumption, parity and menopausal status.

\section{Adverse events, analgesic use, and co-interventions}

These will be measured in a log-book and by structured questioning by the blinded assessor at each follow-up.

\section{Biochemical parameters}

General (cell counts, liver and renal function), inflammatory markers (C-reactive protein, erythrocyte sedimentation rate).

\section{Sample size calculation}

The average VAS pain in a previous clinical trial of symptomatic hand OA similar to the proposed study was 54 $\mathrm{mm}$ (standard deviation $20 \mathrm{~mm}$ ) [43]. The minimal clinically important difference to be detected in OA trials is a
$15 \mathrm{~mm}$ change in VAS pain (out of $100 \mathrm{~mm}$ ) [44]. We will require 38 participants in each group to attain a power of $90 \%$ to detect the minimal clinically important difference (alpha 0.05, two-sided significance). Accounting for an estimated 20\% loss to follow-up, we will recruit 96 participants, 48 in each group.

\section{Statistical analyses}

Analyses will be conducted in Stata v16 or later. An intention-to-treat analysis, including all participants in their randomised groups regardless of their adherence to assigned treatments, will be performed in a blinded fashion. The effect of intervention on pain reduction and other pain and function outcomes measured at multiple time points (for pain: week 4, month 3 and month 6; for secondary pain and function measures, month 3 and month 6) will be analysed using mixed linear regression models, with a random intercept for participant. Models will be adjusted for the baseline measure and the stratifying variables of site and gender, and include categorical terms for time, a term for randomised group and terms for the interaction between randomised group and time. Results will be presented as mean differences between groups at each time point with $95 \%$ confidence intervals, and p-values will also be reported. For measures only taken at baseline and a single follow-up time point, regression models will omit random intercepts and terms for time. Regression modelling assumptions will be assessed graphically. In the case of a gross departure from normality of residuals, ranked based techniques will be applied. As stipulated by OARSI clinical trial recommendations [28], binary logistic regression will be used to assess the effect of intervention on structural progression at 6 months, adjusted for the stratifying variables of site and gender. The outcome of tender/swollen joint count will be analysed via a Poisson model fit via generalised estimating equations with an exchangeable working correlation structure to account for multiple measurements per participant. This model will include the baseline measure and the stratifying variables of site and gender, and include categorical terms for time, a term for randomised group and terms for the interaction between randomised group and time. If more than $5 \%$ of participants are missing their primary outcome, multiple imputation will be applied to account for missing data, with missing values imputed separately by treatment group. Sensitivity analyses will fit outcome regression models additionally adjusted for age, body mass index, and severity of radiographic OA and synovitis if baseline imbalances between randomised groups with respect to these variables are considered clinically important. A sensitivity analysis of the primary outcome will be undertaken to estimate the effect of methotrexate under the assumption 
of hypothetical complete compliance to treatment by applying a two-stage least squares instrumental variables approach [45], where full compliance will be defined as participants taking at least $80 \%$ of their medication.

\section{Data integrity and management}

Data will be collected using prespecified case report forms. All data collected will be kept strictly confidential. Paper-based data will be stored in locked cabinets with secured and restricted access at each study site. Electronic data will be stored in a password-protected database with secured and restricted access. Participants will be identified by study ID and randomisation code, with other information with the potential of identifying individuals removed. Data transfer will be encrypted with all data de-identified. After trial completion, case report forms will be securely archived, and electronic data will be saved on the secure server, password-protected and accessible only to study investigators. There are no planned interim analyses and stopping guidelines.

\section{Dissemination}

Trial results, regardless of statistical significance, will be published in peer-reviewed journals and presented at national and international conferences. Upon publication of the primary manuscript, participants will be informed of their group allocation and provided with the results.

\section{Discussion}

This randomised controlled trial is conducted to determine whether $20 \mathrm{mg}$ methotrexate weekly reduces pain and slows structural progression in participants with symptomatic hand $\mathrm{OA}$ and synovitis, the common inflammatory phenotype of hand OA.

Histological changes in hand OA with synovitis are very similar to those seen in rheumatoid arthritis [22], where methotrexate is first line disease-modifying antirheumatic therapy for most patients with rheumatoid arthritis. Methotrexate is a folate analogue that inhibits dihydrofolate reductase, required for purine and pyrimidine synthesis and cell proliferation [23]. The mechanism of action of methotrexate is considered to be due to inducible apoptosis in synovium, making it an effective treatment for synovitis [46]. Synovial biopsy samples from inflammatory hand OA show intense proliferative synovitis, indistinguishable from rheumatoid arthritis [22]. Increased levels of pro-inflammatory cytokines (such as tumour necrosis factor $\alpha$, interleukin-1 $\beta$ and interleukin-6), reduced levels of anti-inflammatory cytokines (such as interleukin-10 and interleukin-1RA), infiltration of mononuclear cells and adaptive immune cell responses have all been demonstrated within OA fluid and tissue [47-49]. These data suggest that modulating the inflammatory response may be effective as a treatment target for hand OA. Therefore, therapeutics historically used to treat inflammatory arthritis may benefit patients with hand OA and synovitis.

The results from previous clinical trials of tumour necrosis factor blockers provide proof of concept that targeting synovitis is effective in reducing pain and slowing structural progression of hand OA [20, 21]. There is evidence that methotrexate improves symptoms and reduces radiographic progression of rheumatoid arthritis [23], and reduces pain in randomised controlled trials of knee OA [24, 25]. Methotrexate has been in clinical practice for approximately 40 years. Rheumatologists and general practitioners have extensive experience using methotrexate. In clinical practice, the most common reason for methotrexate discontinuation in a 13-year study was gastrointestinal side effects (10.8\%) [50]. Administration of folic acid reduces adverse events [31], while folinic acid rescue can be used to reverse methotrexate [31]. In a systematic review, $3 \%$ of people on methotrexate monotherapy experienced a serious side effect compared with $2 \%$ of placebo-controls [23]. Sixteen percent of people discontinued methotrexate within 52 weeks due to an adverse event, compared with $8 \%$ of placebo subjects [23].

This study will provide high-quality evidence to address whether methotrexate has an effect on reducing pain over 6 months in patients with hand OA and synovitis, a common phenotype of hand OA. The trial has major clinical and public health importance. If found to be beneficial, the study findings will inform international clinical practice guidelines for the management of hand OA. While a positive trial would help to inform clinical guidelines internationally, a negative trial would be highly topical and change current trends in clinical practice.

\section{Abbreviations}

AE: Adverse event; AUSCAN: Australian Canadian Osteoarthritis Hand Index; CONSORT: Consolidated Standards of Reporting Trials; HAQ: Health Assessment Questionnaire; FIHOA: Functional Index for Hand Osteoarthritis; MHQ: Michigan Hand Outcomes Questionnaire; MRI: Magnetic resonance imaging; NSAIDs: Non-steroidal anti-inflammatory drugs; OA: Osteoarthritis; OARSI: Osteoarthritis Research Society International; OMERACT: Outcome Measures in Rheumatology; VAS: Visual analogue scale; WOMAC: Western Ontario and McMaster Universities Osteoarthritis Index.

\section{Acknowledgements}

Not applicable.

\section{Authors' contributions}

Concept and design: YW, AJT, GJ, HIK, CLH, JK, FMC; Study execution and data acquisition: YW, AJT, GJ, HIK, CLH, AEW, JK, FMC; Drafting of the manuscript: YW, FMC; Critical revision of the manuscript for important intellectual content and approval of the final manuscript:YW, AJT, GJ, HIK, CLH, AEW, JK, FMC;

Obtaining of funding: AJT, FMC, GJ, HIK, JK, YW. 


\section{Funding}

The study is funded by a project grant from the National Health and Medical Research Council of Australia (NHMRC, APP1127981). YW is the recipient of NHMRC Translating Research into Practice Fellowship (APP1168185). GJ is the recipient of NHMRC Practitioner Fellowship. AEW is the recipient of the Royal Australian College of Physicians Fellows Career Development Fellowship. FMC is the recipient of NHMRC Investigator Grant (APP1194829). The funder of the study had no role in the study design and conduct of the study; collection, management, analysis and interpretation of the data; preparation, review, or approval of the manuscript; and decision to submit the manuscript for publication.

\section{Availability of data and materials}

Data sharing is not applicable to this article as no datasets were generated or analysed during the current study.

\section{Declarations}

\section{Ethics approval and consent to participate}

Ethics approval has been obtained from Alfred Hospital Ethics Committee (290/17), Monash University Human Research Ethics Committee (10725), University of Tasmania Human Research Ethics Committee (H0016794), Central Adelaide Local Health Network Human Research Ethics Committee (HREC/18/ CALHN/458), and South Metropolitan Health Service Human Research Ethics Committee (RGS0000000573). Participants will only be included after they have provided written informed consent.

\section{Consent for publication}

Not applicable.

\section{Competing interests}

GJ received honoraria for talks from BMS, Roche, AbbVie, Amgen, Lilly, Novartis, and Janssen, and grant for a clinical trial from Covance. The other authors declare that they have no conflict of interest.

\section{Author details}

${ }^{1}$ Department of Epidemiology and Preventive Medicine, School of Public Health and Preventive Medicine, Monash University, 553 St Kilda Road, Melbourne, VIC 3004, Australia. ${ }^{2}$ Menzies Institute for Medical Research, University of Tasmania, Hobart, TAS 7000, Australia. ${ }^{3}$ Rheumatology Group, School of Medicine, University of Western Australia, Perth, WA 6009, Australia. ${ }^{4}$ Department of Rheumatology, Fiona Stanley Hospital, Murdoch, WA 6150, Australia. ${ }^{5}$ The Queen Elizabeth Hospital, University of Adelaide, Woodville, SA 5011, Australia. ${ }^{6}$ Department of Medicine, University of Adelaide, Adelaide, SA 5000, Australia.

\section{Received: 4 October 2021 Accepted: 4 November 2021}

Published online: 15 November 2021

\section{References}

1. Creamer P, Hochberg MC. Osteoarthritis. Lancet. 1997;350:503-8.

2. Dahaghin S, Bierma-Zeinstra SM, Ginai AZ, Pols HA, Hazes JM, Koes BW. Prevalence and pattern of radiographic hand osteoarthritis and association with pain and disability (the Rotterdam study). Ann Rheum Dis. 2005;64:682-7.

3. Haugen IK, Englund M, Aliabadi P, Niu J, Clancy M, Kvien TK, et al. Prevalence, incidence and progression of hand osteoarthritis in the general population: the Framingham Osteoarthritis Study. Ann Rheum Dis. 2011;70:1581-6.

4. Dillon CF, Hirsch R, Rasch EK, Gu Q. Symptomatic hand osteoarthritis in the United States: prevalence and functional impairment estimates from the third U.S. National Health and Nutrition Examination Survey, 19911994. Am J Phys Med Rehabil. 2007:86:12-21.

5. Michon M, Maheu E, Berenbaum F. Assessing health-related quality of life in hand osteoarthritis: a literature review. Ann Rheum Dis. 2011;70:921-8.

6. Zhang W, Doherty M, Leeb BF, Alekseeva L, Arden NK, Bijlsma JW, et al. EULAR evidence-based recommendations for the diagnosis of hand osteoarthritis: report of a task force of ESCISIT. Ann Rheum Dis. 2009;68:8-17.
7. Kloppenburg M, Kroon FP, Blanco FJ, Doherty M, Dziedzic KS, GreibrokkE, et al. 2018 update of the EULAR recommendations for the management of hand osteoarthritis. Ann Rheum Dis. 2019:78:16-24.

8. Bijlsma JW, Berenbaum F, Lafeber FP. Osteoarthritis: an update with relevance for clinical practice. Lancet. 2011;377:2115-26.

9. Kortekaas MC, Kwok WY, Reijnierse M, Huizinga TW, Kloppenburg M. In erosive hand osteoarthritis more inflammatory signs on ultrasound are found than in the rest of hand osteoarthritis. Ann Rheum Dis. 2013;72:930-4

10. Punzi L, Frigato M, Frallonardo P, Ramonda R. Inflammatory osteoarthritis of the hand. Best Pract Res Clin Rheumatol. 2010;24:301-12.

11. Kortekaas MC, Kwok WY, Reijnierse M, Kloppenburg M. Inflammatory ultrasound features show independent associations with progression of structural damage after over 2 years of follow-up in patients with hand osteoarthritis. Ann Rheum Dis. 2015;74:1720-4

12. Kortekaas MC, KwokWY, Reijnierse M, Stijnen T, Kloppenburg M. Brief report: association of inflammation with development of erosions in patients with hand osteoarthritis: a prospective ultrasonography study. Arthritis Rheumatol. 2016;68:392-7.

13. Haugen IK, Slatkowsky-Christensen B, Boyesen $P$, Sesseng $S$, van der Heijde D, Kvien TK. MRI findings predict radiographic progression and development of erosions in hand osteoarthritis. Ann Rheum Dis. 2016;75:117-23.

14. Mathiessen A, Slatkowsky-Christensen B, Kvien TK, Hammer HB, Haugen IK. Ultrasound-detected inflammation predicts radiographic progression in hand osteoarthritis after 5 years. Ann Rheum Dis. 2016;75:825-30.

15. Keen HI, Wakefield RJ, Grainger AJ, Hensor EM, Emery P, Conaghan PG. An ultrasonographic study of osteoarthritis of the hand: synovitis and its relationship to structural pathology and symptoms. Arthritis Rheum. 2008;59:1756-63.

16. Kortekaas MC, Kwok WY, Reijnierse M, Watt I, Huizinga TW, Kloppenburg M. Pain in hand osteoarthritis is associated with inflammation: the value of ultrasound. Ann Rheum Dis. 2010;69:1367-9.

17. Wittoek R, Carron P, Verbruggen G. Structural and inflammatory sonographic findings in erosive and non-erosive osteoarthritis of the interphalangeal finger joints. Ann Rheum Dis. 2010;69:2173-6.

18. Haugen IK, Boyesen P, Slatkowsky-Christensen B, Sesseng S, van der Heijde D, Kvien TK. Associations between MRI-defined synovitis, bone marrow lesions and structural features and measures of pain and physical function in hand osteoarthritis. Ann Rheum Dis. 2012;71:899-904.

19. Chevalier X, Ravaud P, Maheu E, Baron G, Rialland A, Vergnaud P, et al. Adalimumab in patients with hand osteoarthritis refractory to analgesics and NSAIDs: a randomised, multicentre, double-blind, placebo-controlled trial. Ann Rheum Dis. 2015;74:1697-705.

20. Kloppenburg M, Ramonda R, Bobacz K, KwokWY, Elewaut D, Huizinga TWJ, et al. Etanercept in patients with inflammatory hand osteoarthritis (EHOA): a multicentre, randomised, double-blind, placebo-controlled trial. Ann Rheum Dis. 2018;77:1757-64

21. Verbruggen G, Wittoek R, Vander Cruyssen B, Elewaut D. Tumour necrosis factor blockade for the treatment of erosive osteoarthritis of the interphalangeal finger joints: a double blind, randomised trial on structure modification. Ann Rheum Dis. 2012;71:891-8.

22. Belhorn LR, Hess EV. Erosive osteoarthritis. Semin Arthritis Rheum. 1993;22:298-306

23. Lopez-Olivo MA, Siddhanamatha HR, Shea B, Tugwell P, Wells GA, SuarezAlmazor ME. Methotrexate for treating rheumatoid arthritis. Cochrane Database Syst Rev. 2014;2014:Cd000957.

24. Enteshari-Moghaddam A, Isazadehfar K, Habibzadeh A, Hemmati M. Efficacy of Methotrexate on Pain Severity Reduction and Improvement of Quality of Life in Patients with Moderate to Severe Knee Osteoarthritis. Anesth Pain Med. 2019;9:e89990.

25. Wenham CY, Grainger AJ, Hensor EM, Caperon AR, Ash ZR, Conaghan PG. Methotrexate for pain relief in knee osteoarthritis: an open-label study. Rheumatology. 2013;52:888-92.

26. Ferrero S, Wittoek R, Allado E, Cruzel C, Fontas E, Breuil V, et al. Methotrexate treatment in hand osteoarthritis refractory to usual treatments: a randomised, double-blind, placebo-controlled trial. Semin Arthritis Rheum. 2021;51:831-8.

27. Moher D, Hopewell S, Schulz KF, Montori V, Gotzsche PC, Devereaux PJ, et al. CONSORT 2010 explanation and elaboration: updated guidelines for reporting parallel group randomised trials. BMJ. 2010;340:c869. 
28. Kloppenburg M, Maheu E, Kraus VB, Cicuttini F, Doherty M, Dreiser RL, et al. OARSI clinical trials recommendations: design and conduct of clinical trials for hand osteoarthritis. Osteoarthritis Cartilage. 2015;23:772-86.

29. Haugen IK, Østergaard M, Eshed I, McQueen FM, Bird P, Gandjbakhch F, et al. Iterative development and reliability of the OMERACT hand osteoarthritis MRI scoring system. J Rheumatol. 2014;41:386-91.

30. Hoekstra M, Haagsma C, Neef C, Proost J, Knuif A, van de Laar M. Splitting high-dose oral methotrexate improves bioavailability: a pharmacokinetic study in patients with rheumatoid arthritis. J Rheumatol. 2006:33:481-5.

31. Shea B, Swinden MV, Ghogomu ET, Ortiz Z, Katchamart W, Rader T, et al. Folic acid and folinic acid for reducing side effects in patients receiving methotrexate for rheumatoid arthritis. J Rheumatol. 2014;41:1049-60.

32. Visser AW, Boyesen P, Haugen IK, Schoones JW, van der Heijde DM, Rosendaal FR, et al. Instruments measuring pain, physical function, or patient's global assessment in hand osteoarthritis: a systematic literature search. J Rheumatol. 2015;42:2118-34.

33. Dreiser RL, Maheu E, Guillou GB, Caspard H, Grouin JM. Validation of an algofunctional index for osteoarthritis of the hand. Rev Rhum Engl Ed. 1995;62:43s-53s.

34. Bellamy N, Campbell J, Haraoui B, Gerecz-Simon E, Buchbinder R, Hobby $K$, et al. Clinimetric properties of the AUSCAN Osteoarthritis Hand Index: an evaluation of reliability, validity and responsiveness. Osteoarthritis Cartilage. 2002;10:863-9.

35. Fries JF, Spitz P, Kraines RG, Holman HR. Measurement of patient outcome in arthritis. Arthritis Rheum. 1980;23:137-45.

36. Chung KC, Pillsbury MS, Walters MR, Hayward RA. Reliability and validity testing of the Michigan Hand Outcomes Questionnaire. J Hand Surg Am. 1998;23:575-87.

37. Ware JE Jr, Sherbourne CD. The MOS 36-item short-form health survey (SF-36). I. Conceptual framework and item selection. Med Care. 1992;30:473-83.

38. Doyle DV, Dieppe PA, Scott J, Huskisson EC. An articular index for the assessment of osteoarthritis. Ann Rheum Dis. 1981;40:75-8.

39. Hunter DJ, Arden N, Cicuttini F, Crema MD, Dardzinski B, Duryea J, et al. OARSI Clinical Trials Recommendations: Hand imaging in clinical trials in osteoarthritis. Osteoarthritis Cartilage. 2015;23:732-46.

40. Altman RD, Gold GE. Atlas of individual radiographic features in osteoarthritis, revised. Osteoarthritis Cartilage. 2007;15(Suppl A):A1-56.

41. Cicuttini FM, Baker JR, Spector TD. The association of obesity with osteoarthritis of the hand and knee in women: a twin study. J Rheumatol. 1996;23:1221-6.
42. Visser AW, Bøyesen P, Haugen IK, Schoones JW, van der Heijde DM, Rosendaal FR, et al. Radiographic scoring methods in hand osteoarthritis-a systematic literature search and descriptive review. Osteoarthritis Cartilage. 2014;22:1710-23.

43. Kroon FPB, Kortekaas MC, Boonen A, Bohringer S, Reijnierse M, Rosendaal $\mathrm{FR}$, et al. Results of a 6-week treatment with $10 \mathrm{mg}$ prednisolone in patients with hand osteoarthritis (HOPE): a double-blind, randomised, placebo-controlled trial. Lancet. 2019;394:1993-2001.

44. Tubach F, Ravaud P, Martin-Mola E, Awada H, Bellamy N, Bombardier C, et al. Minimum clinically important improvement and patient acceptable symptom state in pain and function in rheumatoid arthritis, ankylosing spondylitis, chronic back pain, hand osteoarthritis, and hip and knee osteoarthritis: results from a prospective multinational study. Arthritis Care Res. 2012;64:1699-707.

45. Maracy M, Dunn G. Estimating dose-response effects in psychological treatment trials: the role of instrumental variables. Stat Methods Med Res. 2011;20:191-215.

46. Nakazawa F, Matsuno H, Yudoh K, Katayama R, Sawai T, Uzuki M, et al. Methotrexate inhibits rheumatoid synovitis by inducing apoptosis. J Rheumatol. 2001;28:1800-8.

47. Goldring MB. Anticytokine therapy for osteoarthritis. Expert Opin Biol Ther. 2001;1:817-29.

48. Smith MD, Triantafillou S, Parker A, Youssef PP, Coleman M. Synovial membrane inflammation and cytokine production in patients with early osteoarthritis. J Rheumatol. 1997;24:365-71.

49. Myers SL, Brandt KD, Ehlich JW, Braunstein EM, Shelbourne KD, Heck DA, et al. Synovial inflammation in patients with early osteoarthritis of the knee. J Rheumatol. 1990;17:1662-9.

50. Kinder AJ, Hassell AB, Brand J, Brownfield A, Grove M, Shadforth MF. The treatment of inflammatory arthritis with methotrexate in clinical practice: treatment duration and incidence of adverse drug reactions. Rheumatology (Oxford). 2005;44:61-6.

\section{Publisher's Note}

Springer Nature remains neutral with regard to jurisdictional claims in published maps and institutional affiliations.
Ready to submit your research? Choose BMC and benefit from:

- fast, convenient online submission

- thorough peer review by experienced researchers in your field

- rapid publication on acceptance

- support for research data, including large and complex data types

- gold Open Access which fosters wider collaboration and increased citations

- maximum visibility for your research: over $100 \mathrm{M}$ website views per year

At BMC, research is always in progress.

Learn more biomedcentral.com/submissions 